\title{
Politik gaya Sengkuni dan estetika Semar kajian antropologi sastra terhadap pemilu legislatif
}

\author{
Sengkuni political style and Semar aesthetic in literature anthropology to \\ legislative election
}

\author{
Suwardi Endraswara \\ FBS, Universitas Negeri Yogyakarta, Indonesia \\ Karangmalang, Yogyakarta 55281. Telepon: (0274) 550843 \\ E-mail: suwardi endraswara@yahoo.com
}

\begin{abstract}
This article aims to explain two unique political actions, namely Sengkuni style and Seamr aesthetic. Both styles were viewed from litterature anthropology perspective. This methapor provides authentic data from 2009 election, expected to be a reflection the 2014 election. The study shows that politic, culture, and litterature were conected to each other, produces methapor in two political style. First, in this transitional era, sengkuni style is more favorable in targetting people, especially the middle class-men. Secondly is semar aesthetic style, more suitable for upper class-men group, those who hold their tradition tightly. This style suits better to pro-people type of leader. In conclusion, researcher found that both style has its strength and weakness, mostly depends on the targetted group in the community.
\end{abstract}

Keywords: politics, style Sengkuni, Semar aesthetic and anthropological literature

\begin{abstract}
Abstrak
Tulisan ini bertujuan memaparkan tindakan politik yang unik, memanfaatkan gaya Sengkuni dan estetika Semar. Kedua gaya ini ditinjau dari sisi antropologi sastra. Politik metaforis ini menyajikan data otentik pada Pemilu 2009, dengan harapan dapat dijadikan kaca benggala pada Pemilu 2014. Dari pembahasan, tampak bahwa politik, budaya, dan sastra memang amat memiliki keterkaitan yang menghasilkan dua gaya politik yang bersifat metaforis. Pertama, di era yang memang transisional politik ini, mungkin gaya Sengkuni yang lebih cocok, terlebih lagi pada sasaran rakyat (wong cilik). Kedua, gaya estetika Semar, lebih mempan ditujukan kepada segmen masyarakat yang memegang teguh tradisi, terlebih para priyayi. Gaya estetika Semar, lebih menekankan pemimpin yang ngawula, berpihak pada rakyat. Atas dasar pembahasan, dapat disimpulkan bahwa kedua gaya politik pileg itu tidak ada yang lebih ampuh. Seluruhnya tergantung segmen masyarakat yang disasar.
\end{abstract}

Kata kunci: politik, gaya Sengkuni, estetika Semar, dan antropologi sastra

\section{Pendahuluan}

Politik itu tidak mungkin steril dari berbagai pengaruh, seperti ihwal estetik, etik, dan kapitalistik. Pengaruh-pengaruh itu menandai bahwa budaya politik dari sisi antropologi sastra, senantiasa menggunakan gaya-gaya tradisi dan sastra untuk mencari kemenangan. Antropologi berarti kajian manusia, melalui aspek sosial, budaya, sastra, bahasa, arkeologi, fisik, dan sebagainya (Keesing 1992:2-3). Dalam mengkaji manusia, dapat melalui karya sastra. Sastra adalah kegiatan kreatif, sebuah karya seni (Wellek \& Warren 1989:3). Upaya mempelajari sastra dari sisi antropologi ini dapat disebut antropologi sastra. Munculnya antropologi sastra, didorong oleh pemikiran Ernst Cassier (1956:44) tentang hakikat manusia sebagai animal symbolicum. Karya sastra adalah ekspresi gagasan tentang hidup manusia melalui berbagai symbol. Gagasan ini, menurut Ratna (2004:353) memunculkan sebuah disiplin baru, yang disebut antropologi sastra, senada dengan istilah psikologi sastra dan sosiologi sastra.

Gagasan antropologi sastra merupakan pengembangan studi sastra dari kacamata antropologi. Hal ini dipertegas lagi dengan pemikiran Paul Benson (1993) dalam bukunya berjudul Anthropology and Literature, dia mencoba mengaitkan antropologi dengan sastra untuk mengungkap kehidupan manusia. Selanjutnya, gagasan baru itu juga menarik perhatian Ahimsa-Putra (2004) dalam bukunya berjudul Strukturalisme Levi-Strauss Mitos dan Karya Sastra. Dia menawarkan kajian struktural 
terhadap mitos, termasuk folklore, dan karya sastra. Berbagai hal ini sering dimanfaatkan oleh para politikus, untuk meraih suara secara simbolik.

Menjelang tahun politik (2013-2014) ini, tampaknya berbagai upaya para pelaku politik sudah mulai menerapkan jurus masing-masing. Untuk itu, ada baiknya memang para pelaku menengok Pemilu lima tahun yang lalu (2009). Hal ini seperti terungkap dalam puisi Jawa sebagai berikut.

Jujur iku dadi prabot ing Pemilu

Resik uga ora

Apameneh dhemokratis

Para botoh kudu dagang kulak larang

Pileg iku saya bosok gawe ngelu

Kabeh naker rega

Tanpa isin nora lamis

Rakyat ngelak caleg ngoyak kursi bobrok

(dokumen Sarip, April 2009)

Terjemahan:

Jujur itu menjadi bekal Pemilu

Bersih juga penting

Terlebih lagi demokratis

ibarat para pedagang harus membeli mahal

Pemilu legislatif semakin busuk membuat pusing

Semua memasang harga

Tidak tahu malu tanpa basa-basi

rakyat semakin haus (uang) ketika caleg mengejar kursi rusak

Dua bait puisi tersebut diperoleh dari seorang bernama pak Sarip, seorang pemain jathilan. Dia sering menjadi penthul, hingga gemar menulis puisi Jawa (macapat), sebagai iringan lagu jathilan. Apa saja dia tulis, sesuai momen, termasuk Pileg 2009 yang menurut pandangan dia kurang bersih. Banyak pihak ikut menyetujui bahwa Pileg di Yogyakarta waktu itu jauh dari bebas, demokratis, jujur, dan bersih. Lewat puisi tersebut, merepresentasikan gagasan Ratna (2005:432) bahwa ada kedekatan antara sastra dan budaya. Pemakaian estetika dalam politik pragmatis sulit ditawar-tawar lagi.

Sarip (informan), ketika Pileg berlangsung harus mengantongi iming-iming (tawaran) dari tiga partai, ditambah lagi dari pemerintah yang sedang berjalan. Tiga partai yang terang-terangan membeselkan amplop panjang, yaitu Golkar, PPP, dan PKB. Kata pak Sarip, besaran amplop cukup lumayan, di atas 25 ribu. Baginya yang tergolong sebagai pemegang kartu gakin (keluarga miskin), uang sejumlah itu cukup lumayan. Ketika didesak pertanyaan, lalu mencontrengnya bagaimana? "Nggih manut ati kula. Lha niki kula nggih bar nampa BLT, kompor gas, menda nggih tau. Dados pokoke nggih waton nyontreng sing cocog kalih ati. Lha kabeh nggih menehi, tur kula butuh.” Artinya, dia mencontreng menurut isi hatinya. Dia juga habis menerima bantuan langsung tunai (BLT), berupa kompor gas dan kambing. Jadi yang penting asal mencontreng yang cocok dengan hati. Semua partai juga memberi dan dia juga membutuhkan.

Sungguh layak, kalau pria berputra dua itu dalam suasana bimbang ketika nyontreng. Tampaknya, di sekeliling dia, nyontreng dengan model "jual beli", siapa yang terbanyak, disontreng, amat memungkinkan. Maka, ketika njathil di bulan 29 Mei 2009, bertepatan dengan bersih desa, dia juga menggubah lagu lagi amat sederhana, tetapi nuansanya tetap menyentuh sendi-sendi pileg.

Adhuh bingunge atiku bar nampa

Dhuwit sontrengan rasane njur lega

Aku wis lali pokoke milih

Angger ra lali mring Gusti kang suci 


\author{
Ayo pra warga bangkit merti desa \\ Aja dha kemba le nyontreng sing tata \\ Dhemokrasine nggo nyenyeneng ati \\ Kabeh ja lali mring Gusti kang suci \\ (dokumen Sarip, Mei 2009) \\ Terjemahan: \\ Aduh hatiku bingung setelah menerima \\ Uang sontrengan menjadi lega \\ Saya sudah lupa yang penting memilih \\ Yang penting tida lupa pada Tuhan Maha Suci \\ Mari para warga bangkit membersihkan desa \\ Jangan ragu menyontreng yang tertata \\ Demokrasi biar mennyenangkan hati \\ semua agar tidak lupa kepada Tuhan Maha Suci
}

Apa pun fenomena yang muncul, tampaknya cukup mendorong kreativitas seniman lapangan. Sarip yang tidak mengenyam pendidikan tinggi, sebagai petani cengkih, ternyata bisa berkarya cukup ekspresif. Dia berhasil memotret situasi Pileg, yang katanya bisa membuat bingung. Namun, yang menarik bagi dia, ternyata segalanya perlu disikapi dengan rasa eling kepada Tuhan. Tuhan adalah maha suci.

Entah salah siapa, ternyata memang Pileg 2009 telah menyisakan berbagai masalah bangsa. Pendewasaan rakyat terhadap pesta demokrasi, seakan semakin kandas, setelah dicoreng dengan sontrengan model bagi-bagi dana. Terutama, di wilayah pak Sarip juga ada partai lain, yaitu PDIP yang masuk ke RT, tiba-tiba memberikan "suntikan" 300 ribu. Uang ini, telah dibelikan kain geber (tutup), yang dipakai menutup jika ada pentas jathilan, orang punya hajat, dan membuat panggung bersih desa.

Rakyat telah dimanjakan dengan kucuran dana, entah untuk kolektif dan pribadi, tetapi menciptakan potret buram demokrasi. Jika di masa orde baru, kata Husken (Antlov \& Cederroth 2001:20-26) masyarakat semacam di-screening, digiring harus mencoblos Golkar, sekarang telah lari dari kungkungan itu. Namun, tidak berarti masyarakat bebas, melainkan kalau orde baru sang kapitalis ragu-ragu, di era reformasi sudah semakin blak-blakan. Bahkan ada anggapan, berani mencalonkan diri sebagai caleg di Yogyakarta ini, harus kandel bokonge (tebal pantatnya, artinya kaya) dan berani cucul (berani mengeluarkan uang) tidak owel (kikir).

Dengan multi partai, persaingan memang semakin tajam. Tiap satu suara, seakan telah dihitung dengan kalkulasi nol-nya berapa. Masyarakat Yogyakarta, sebagian telah terkontaminasi dengan iklim keruh. Apalagi berhadapan dengan rakyat miskin, tentu semakin dibaca oleh "kapitalis gundul", terang-terangan. Siapa yang sakunya tebal, kemungkinan besar yang akan menduduki caleg, terusmenerus, entah sampai kapan. Perlu dicatat, keberhasilan kepemimpinan masa depan, seakan menunggu "senggama terbuka", antara politikus, rakyat, dan kapitalis. Ketika rakyat mencoba berekspresi secara estetik, hanyut dalam politik praktis, lenyaplah mereka ditelan paham kapitalistik.

Pileg yang dikaitkan dengan istilah Jawa ngelu (pusing) tampaknya bermakna pileg (influensa). Artinya, Pileg benar-benar melelahkan, menyebar virus materialistik, dan membuat orang pusing. Terlebih dengan hadirnya janji-janji jurkam yang semakin terang-terangan, seakan percaturan politik selalu identik dengan uang. Bahkan di kampung Sumarji, katanya, sempat beredar isu, satu coblosan tergantung nolnya berapa.

Pembiasaan money politic itu telah meracuni warga, hingga sebagian ada yang enggan mencoblos, jika tanpa ada uang dari caleg mana pun. Pada saat itu, rumor dan segala rembug di jalan, tempat 
ronda, tempat petan tuma, dunia kerokan, dan lain-lain muaranya pada kata-kata Jawa: "Entuk pira?" (Dapat uang berapa?). Kata-kata ini, yang diperkirakan sebagai balas jasa mencontreng, jelas menodai demokrasi.

Jadi, Pileg di Yogyakarta tidak seperti biasanya, melainkan banyak riak-riak politik yang kotor. Dicermati, seiring kemajuan teknologi dan informasi, Pemilu 2009 ini penuh strategi dan taktik untuk menarik perhatian masyarakat. Yogyakarta sebagai kota budaya, warisan keraton, dan kawasan mistik kejawen telah dibidik dan dipoles oleh para caleg untuk menggalang simpatisan dengan cara-cara yang kurang bermartabat, sebab ada semacam pemaksanaan, tawar-menawar, penggiringan, intimidasi kecil, yang ujung-ujungnya pada materi.

Berbagai cara mereka lakukan, yang telah menciptakan suasana Pileg itu riuh. Lebih dari itu, di sanasini orang semakin terjepit pada kubangan budaya Jawa: ewuh pekewuh. Maksudnya, kalau sudah diberi sesuatu, jika tidak mencontreng partai pemberi, menjadi tidak enak. Padahal, ada yang menerima lebih dari tiga partai, sehingga rasa tidak enak selalu menggores hati masing-masing pemilih. Tidak seluruh kontestan berjiwa materialis, begitu pula pemilihnya. Dari berbagai pesan yang diusung oleh komunikator, kader, dan media meraih sukses, setelah direnungkan ternyata muaranya mengikuti dua gaya politik, yaitu: (1) gaya Sengkuni dan (2) gaya estetika Semar, kedua gaya metaforik ini, tampaknya yang mewarnai percaturan Pileg yang melelahkan itu.

\title{
Politik gaya Sengkuni bertopeng tradisi dan berpayung agama
}

Sebuah cerpen berjudul Sang Kuni karya Tan Tjin Siong (2003). Karya ini telah dimuat di Memorandum (1997). Intinya, cerpenis jelas mengidentikan tokoh Sengkuni dengan Sang Kuni (tokoh) yang akan diangkat sebagai direktur perusahaan. Menurut cerpenis, figur Sang Kuni lebih cocok menjadi pemimpin saat ini. Di bawah ini kutipan deskripsi apa dan siapa Sang Kuni menurut pandangan cerpenis.

\begin{abstract}
Menjadi kebiasaan Sang Kuni, bila diajak bicara, ia makin nyerocos. Seakan-akan tidak ada yang bisa menghentikan bicaranya. Ada keistimewaan yang dimiliki Sang Kuni, bila berbicara sering menghanyutkan yang diajak bicara. Tak jarang yang menangis kalau cerita sedih, dan tertawa terpingkal-pingkal bila cerita lucu.Sejak itu Sang kuni kemana-mana 'menjual omongan'. (hal. 112)
\end{abstract}

Penulis memandang cerpenis Cina itu telah paham genetika dan profil Sengkuni di Jawa. Figur Sengkuni memang julig, artinya cerdik, yang serba hendak menguntungkan diri sendiri atau golongannya. Luar biasa gaya Sengkuni itu. Kata-kata manis selalu memoles suasana, hingga orang lain terpikat. Dalam Pileg tahun ini, ternyata figur Sengkuni itu berkeliaran, baik oleh caleg sendiri maupun para tim sukses.

Nama yang sebenarnya Sengkuni di dalam kitab Mahabharata adalah Sakuni, kemudian dalam pedalangan berubah menjadi Sengkuni untuk memudahkan pengucapannya. Kitab Purwacarita menyebutnya Trigantalpati. Kitab Pustakaraja menamakan Suman, ia adalah putra Prabu Keswara, juga disebut Prabu Swela, Prabu Gandara yang berkedudukan di kerajaan Gandaradesa (Harghana \& Aji 2002:104). Sengkuni memang cerdas IQ-nya. Dia pintar mengolah kata, bahasa polesan telah dia hafalkan, Bbahasa racun dia balut menjadi madu, agar pihak lain terpikat. Kesuksesan yang dibangun, atas dasar kecerdikan. Dia seakan-akan menguasai psikologi massa. Maka gaya untuk kemenangan dirinya ditempuh dengan aneka rupa, yang seakan-akan sah. Karena wataknya yang jahat dan selalu mendambakan jabatan yang tinggi, maka Sengkuni setiap hari kerjanya hanya merangkai siasat untuk memfitnah dan menjatuhkan kedudukan orang lain. Suatu hari ia ingin membalas sakit hatinya ketika dikalahkan Pandu. Sengkuni kemudian memfitnah Pandu dengan melapor Prabu Tremboko raja Pringgondani yang sebenarnya masih siswanya Prabu Pandu. Putra-putra Tremboko antara lain Harimba, Brajadenta, Brajamusti, Brajamikaipa, dihasut. Mereka ditakut-takuti akan dibinasakan oleh Pandu. Sebaliknya kepada Pandu ia melapor bahwa putra-putra Pringgondani hendak menyerang Astina. 
Dari narasi kehidupan Sengkuni, terlihat mucul dalam pentas Pileg. Berbagai Siasat caleg dari partai gurameh sampai partai gurem, hampir sulit meninggalkan gaya Sengkuni. Berbagai siasat, hasutan, fitnah kecil, dan omongan licik selalu dikumandangkan. Janji-janji, selalu diketengahkan baik saat kampanye terselubung maupun kampanye terbuka. Muara dari gaya Sengkuni itu, tidak lain adalah upaya "membunuh" lawan politik dengan manisnya mulut.

Daya kreasi mulai dari pemasangan gambar caleg, pemakaian ungkapan, tonjolan-tonjolan program, sampai iklan-iklan selalu cerdik. Di kampung saya, gaya Sengkuni, dipelopori oleh partai besar dengan cara menelusup ke RT ikut pertemuan lapanan. Di tempat itu mereka melakukan pyur-pyur, dengan janji akan mengaspal jalan kampung, apabila kelak jadi. Sampai laporan ini saya tulis, ternyata aspal itu belum terwujud. Baru penjelasan pak Kadus, bahwa jalan yang akan diaspal sudah diukur, entah kapan terwujudnya.

Pyur-pyur semacam itu adalah bentuk money politics dengan aneka kedok, antara lain ritual, agama, ekonomi, dan sosial. Terbukti, caleg dari Partai Demokrat memberikan dana Rp. 100.000,- untuk kampung Juron Bantul, dengan dalih uang itu mohon digunakan ketika kampung menjalankan bersih desa. Ketika warga saya mintai konfirmasi, dijawab: "Ya diterima, orang dikasih, perkara nyontreng apa, nanti. Soalnya, warga saja kalau bersih desa mau bayar Rp. 200.000,- per KK, untuk mengundang dalang wayang kulit, caleg kok cuma beri segitu. Ya mangga terserah nurani masingmasing."

Caleg partai Golkar wanita juga gigih masuk ke pengajian ibu-ibu, memberikan pyur-pyur berkedok agama Islam, dengan memberikan Al Quran. Gaya Sengkuni ini, masih dihias lagi dengan pura-pura memberikan pengajian singkat. Oleh karena dia anak seorang anggota DPRD tahun lalu, tentu gaya Sengkuni semakin jitu ke arah politik berlindung bagaikan pohon beringin yang rindang, hendak meneruskan keberhasilan ayahnya. Selain itu, caleg wanita itu juga masuk ke perkumpulan ibu-ibu dan TPA masjid dengan cara memberikan buku Iqra' agar ibu-ibu tertarik pada partai beringin itu.

Dari kisah itu, apabila Antlov (2001:259) pernah mencatat hadirnya transisi demokrasi yang diikuti krisis moral kepemimpinan, memang tidak salah. Gaya Sengkuni yang penuh muslihat jitu, telah menjawab, bahwa moralitas rakyat Yogyakarta ternyata dapat ditukar gaya reformasi ironik ini. Dikatakan ironik, ketika reformasi menghendaki kepemimpinan bersih, jika figur yang akan berkecimpung dengan undang-undang telah "kotor moral", bagaimana? Pada saat caleg mampu membaca tradisi dan agama sebagai kendaraan merengkuh kursi, yang nota bene materi yang bermain, kelak akan jadi apa negeri ini.

\section{Sengkuniologi sangat menggiurkan}

Sumantri \& Waluyo (1999:145-146) mempunyai simpulan bahwa Sengkuni itu tokoh yang licik, dengki, dan pengecut. Manuver politik yang dilontarkan Sengkuni selalu menjelekkan pihak Pandawa. Apa pun alasannya, gaya Sengkuni demikian ternyata banyak mewarnai Pileg. Orang Jawa bilang, ada watak tidak terpuji yang mirip Sengkuni yaitu drengki, srei, jail, methakil, mbedhidhil, dan uthil.

Kader partai "kelas bawah", pun yang me-nyengkuni ada. Seorang wanita, yang berupaya keras menyebar foto-foto kecil di arisan Dasa Wisma, sempat berlagak Sengkuni: "Niki lo Bu, dicoblos ngriki. Niki pun jelas sae, timbang partai sanese, akeh ndobose. Yen teksih badhe PKB, pecah ta Bu, dha boten mikir wong cilik. Niki lo. Piyambake dhosen, sae, blaba, mangke yen dados ibu-ibu kula usulke piknik Taman Mini. Pun, sesuk awan njenengan gratis pirang-pirang bus, mlebu Alun-alun ler Yogya. Sesuk langsung pidhatone SBY, nggih!” Ajakan dan bujukan itu terekam komplit oleh ibu-ibu yang dibeseli gambar caleg. Penuh untaian manis dan janji. Daripada ramai berdebat masalah caleg, Tini (informan) yang ikut menerima gambar itu memilih diam. Dia tidak setuju dan juga tidak menolak, khawatir kalau merenggangkan hubungan sosial. Jadi, biarpun ada bujukan Sengkuni dari pengurus Dasa Wisma, Tini tetap tidak mudah tergiur. 
Tutur kata Sengkuni, selalu tak lepas dari pengalaman hidup panjangnya. Dia hidup selalu dengan cara bohong, demi memperoleh kemenangan. Prabu Pandu pun begitu percaya omongan Sengkuni, bahwa Astina dikatakan akan diserang musuh. Untuk meyakinkan hal itu, Pandu segera mengutus patih Gandamana agar menemui Prabu Tremboko dan menanyakan kebenaran cerita Sengkuni tadi. Akhirnya karena takut keburukannya ketahuan, sekali lagi Sengkuni menemui Harimba bersaudara agar segera menghabisi Gandamana. Karena putra Pancala itu sangat sakti, Sengkuni membuat cara Gandamana harus dibuatkan lobang jebakan. Kisah itu kemudian dikenal dengan nama lakon Gandamana Luweng, karena atas hasutan Sengkuni, putra-putra Pringgondani menangkap Gandamana kemudian diceburkan ke dalam luweng lalu ditimbun dengan batu.

Bagi raja yang tidak cerdas daya instingnya, mungkin mudah yakin pada omongan Sengkuni yang manis di bibir. Buktinya, setelah seluruh gaya Sengkuni diimplementasikan, Prabu Pandu pun tergiur dan lupa diri. Akibatnya, karena kedudukan patih kosong, Prabu Pandu mengangkat Sengkuni menjadi patih di Astina. Pandu kemudian menyerang Pringgondani sehingga terjadilah perang Pamuksa, yaitu perangnya guru dan murid antara Prabu Pandu dan Prabu Tremboko. Di dalam perang Pamuksa itu, Prabu Tremboko gugur dan menyulut dendam putra-putra Pringgondani terhadap Pandu.

Alkisah, Raden Gandamana yang berhasil menyelamatkan diri, ia kembali menghadap Prabu Pandu, karena jabatan patih sudah diserahkan kepada Sengkuni, Gandamana pulang ke kepatihan dengan tangan hampa. Ketika sampai di rumah, Gandamana terkejut karena di situ sudah ada Sengkuni yang hendak memperkosa istri Gandamana. Bahkan karena tindakan Sengkuni yang senonoh itu, istri Gandamana bunuh diri. Melihat Dewi Candrarini istrinya meninggal dengan patrem masih menancap di dadanya, darah Gandamana mendidih seketika. Sengkuni yang semula berwajah tampan itu dihajar habis-habisan sehingga tubuhnya menjadi rusak.

Begitulah gaya atau trik Sengkuni yang benar-benar penuh bisa. Mulyono (1979:70) Sengkuni yang "klemak-klemek" dan penuh fitnah, merupakan gambaran watak manusia penghasut. Dia tukang fitnah, yang mengolah suara tampak manis. Sesuai asal kata Sengkuni, dari Sakuni (saka, artinya asal) uni (ucapan). Jadi segala ucapan Sengkuni memang penuh tipu maut.

Sesuai jiwa Sengkuni, gila kekuasaan, dengan semangat menghasut, PDIP pernah mengkritisi BLT terlalu kecil, dan anehnya mereka justru pyur-pyur dengan jurus ekonomi dengan cara "mancing bersama" di aliran sungai Bantul, dengan terlebih dahulu diceburkan lele dan bawel seberat 1 ton, hingga warga bergegas mengeroyok dengan pancing. Walhasil, tidak hanya orang tua, melainkan juga anak kecil yang belum punya hak pilih ikut ramai memancing. Politik membangun citra ala Sengkuni ini, juga diikuti PBB dengan gaya pengobatan gratis.

Anehnya, gaya ini juga diikuti oleh caleg Golkar kawakan, G Pardiman, bahkan sudah di luar kampanye, masih mengajak mancing bersama dengan kedok Pardiman Center, serta dibumbui hadiah seperti mini compo, TV, HP dll. Pada akhirnya, tokoh ini memang sukses meraih suara banyak dan jadi. Hal ini berarti rakyat tunduk pada gaya jitu. Apa pun alasannya, gaya demikian tetap memanjakan rakyat, membuat hati ketagihan, dan selalu membangun desain kapitalistik.

Upaya bermain Sengkuni ria, kiranya sulit dibendung ketika Pileg berlangsung. Yang unik, pada masing-masing caleg memiliki Sengkuni-Sengkuni, hingga harus bertaruh dan bertarung. Kampung saya yang semula berbasis PKB terlihat pecah, sejak Gusdur "berkelai" dengan Muhaimin, tiba-tiba gaya Sengkuni muncul ketika PKNU hadir menaklukkan para kyai. Dia mengobral janji dengan semangat baru, hidup baru, dan baru-baru lain dengan memberi pyur-pyur berupa penanggalan tahun 2009. Oleh karena warga jadi bingung, riuh, saling menggunjing, maka sesuai karakter gaya Sengkuni memang tidak suka apabila partai lain sukses di kampung saya ada "larangan" memasang gambar partai apa pun dengan dalih supaya netral. Ketika ada PKNU yang dianggap rival PKB, melanggar kesepakatan, gambar PKNU dirusak dan dicari siapa yang memasang malam hari itu. Yang lebih parah lagi, di tengah keruhnya suasana, ada gaya Sengkuni lain yang diam-diam memasang partai Gerindra, hingga memunculkan intrik berkepanjangan. Hasil akhir, memang PKNU yang ungggul diikuti Demokrat. 
Yang perlu direnungkan, gaya Sengkuni memang julig. Hingga pernah terjadi Prabu Pandu yang menganggap bahwa tindakan Gandamana dianggap bersalah karena menghakimi Sengkuni tanpa sepengetahuannya. Karena itu sebagai hukumannya, Gandamana diusir dari Astina. Gandamana menerima hukuman itu lalu kembali ke negara Pancala. Ketika Prabu Pandu mangkat dan tahta Astina dititipkan kepada Drestarata, Sengkuni mulai menghasut Kurawa agar menuntut secara resmi negara Astina. Dengan berbagai cara yang licik dan jahat Sengkuni berhasil menyingkirkan Pandawa dari Astina dan menampilkan Duryudana sebagai kandidat raja Astina (Lakon Bale Segalagala). Setelah Duryudana resmi menjadi raja Astina, kejahatan Sengkuni kian menjadi jadi. la pernah berbuat tak senonoh dengan Dewi Kunti dengan meremas payudaranya, sehingga Kunti bersumpah tidak akan mengenakan semekan bila tidak dengan kulitnya Sengkuni. Berulang kali Sengkuni dan Kurawa berusaha melenyapkan Pandawa, namun mereka selalu gagal.

Sengkuni bukan hanya ahli siasat dan ahli pemerintahan, tetapi juga mahir dalam olah keprajuritan. Ia mempunyai senjata berupa Cis dan memiliki aji yang mampu mendatangkan beribu-ribu binatang buas. Namun akhirnya ia juga mati dikuliti oleh Werkudara di dalam perang Bharatayuda. Kulitnya diserahkan kepada Dewi Kunti untuk melunasi kaulnya, sedangkan bangkai Sengkuni yang tak berbentuk itu dihancur lumatkan dengan gada Rujakpolo. Dari kisah ini, sebagai rakyat yang telah terkena Sengkuni-isme, memang perlu waspada. Pada waktu gaya itu sukses, hingga caleg-caleg berhasil menduduki kursi, jangan-jangan gaya Sengkuni muncul lagi.

Sengkuni memang kaya siasat untuk memperoleh kekuasaan. Caleg dan kader partai Demokrat, ketika SBY hadir di Alun-alun Utara Yogyakarta, sengaja menggiring warga kampung dengan bus gratis. Kelicikan Sengkuni ternyata amat mempan, buktinya kampanye tersebut sempat melalui pengamanan ketat, sebab yang hadir tidak semata-mata ketua dewan pembina, tetapi sekaligus presiden. Figur incumbent ini berkeliling, biarpun izin, tetapi telah diuntungkan dengan siasat yang selalu diuntungkan. Anehnya, partai lain yang sebagai challenger dan Panwaslu seperti terkena gendam, hanya greneng-greneng saja.

Yang unik lagi, gaya foto caleg banyak diedarkan sembunyi-sembunyi door to door. Intinya, foto itu diberikan pada masyarakat, lalu disuruh menyimpan baik-baik. Pada waktu nyontreng, foto itu harus dibawa dan gambar itu yang harus dipilih. Bahkan selama tiga hari tenang, banyak caleg yang melakukan "serangan fajar" lewat SMS dan telepon. Padahal sebelumnya, cara-cara pencairan dana putera bupati sedang dipermasalahkan oleh berbagai pihak, lantaran cepat cair. Roy Suryo pun ikutikutan menggunakan "serangan fajar", dan DPD harus nyontreng Sulistya, biarpun caleg terakhir ini harus ambruk. Dengan ungkapan kata-kata halus, filosofi, mereka mengobral janji lewat SMS. Terakhir, di masa tenang beberapa caleg masih mengajak mancing bersama berhadiah motor dengan kedok LSM yang dia pimpin sebagai bentuk kampanye terselubung.

\section{Politik gaya estetika Semar}

Rama Sindhunata (1998:1) pernah menulis makalah dalam sebuah seminar sastra tentang "mengarang dengan estetika Semar". Kata dia,selama bertahun-tahun dia membuat karya, novel misalnya, seperti Anak Bajang Menggiring Angin dan Abure Kupu-kupu Kuning selalu memanfaatkan estetika Semar. Paling tidak, menurut dia ada dua hal yang terpenting dalam estetika Semar, yaitu: (1) mengarang dengan semangat kerendahan hati (anoraga), seperti Semar, dan (2) berjiwa pamomong, sebagaimana Semar adalah dewa ngejawantah, selalu memayungi satria yang sukses.

Belajar dari dua hal itu, ternyata semangat Pileg legislatif di Yogyakarta pun juga menggunakan estetika Semar. Semangat tokoh kejawen tulen ini diresapi oleh sejumlah caleg dan tim suksesnya. Dengan permainan kata Jawa, ungkapan merakyat, mereka kemas seakan-akan telah menjadi Semar, yaitu rendah hati dan sebagai pamomong sejati. Idiomatik Semar yang gemar berucap: mblegeduweg ugeg-ugeg sadulita hemel-hemel, heh-hah-hah, pun disanggit dalam berbagai reklame kampanye. Dalam suluk wayang Ki Hadisugito menggambarkan Semar sebagai berikut. 


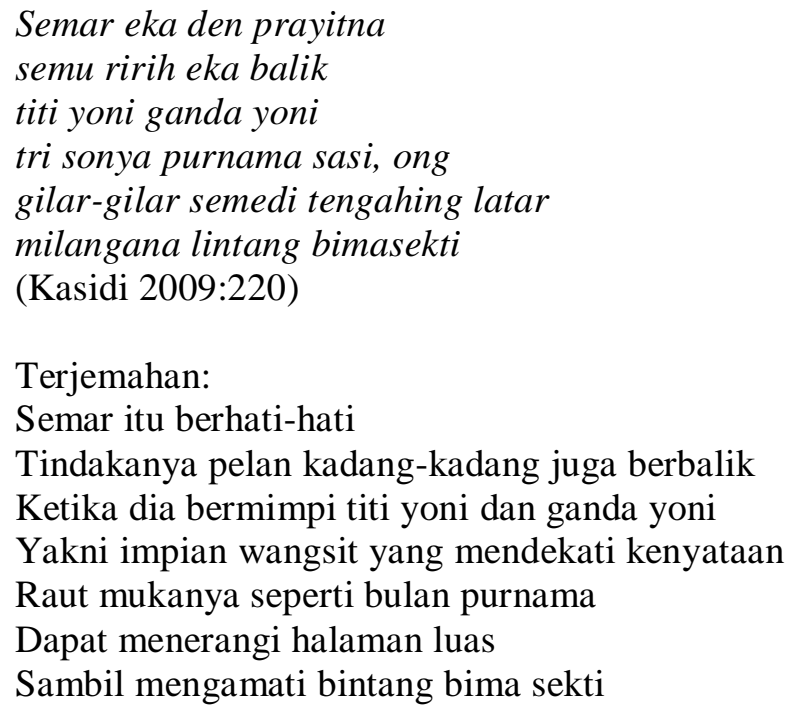

Inti dari sulukan itu, melukiskan bahwa Semar itu figur yang selalu hati-hati, agar selalu halus dalam hidup ini. Semar biasanya keluar dalam suasana "eka balik", yaitu gara-gara menjelang orang bermimpi titi yoni, ada bau-bauan semerbak dari yoni. Saat itu ada seorang yang semedi, menyatukan tiga dunia yang tersinari rembulan. Petapa itu seperti sedang menghitung bintang Bima Sakti. Jadi, figur Semar itu selalu momong satria yang betah bertapa, selalu hati-hati hidupnya. Nuansa mistik kejawen memang muncul dari estetika Semar itu.

Estetika Semar tergolong tokoh yang hebat. Watak Semar selalu rendah hati (Anoraga) sebagai pamomong satria ahli bertapa. Caleg yang menggunakan estetika Semar, juga sederhana dan tidak berlebihan. Dalam dunia politik, Semar cenderung santun, bersih, dan tegas. Jika tokoh ini dibiarkan, justru bertindak demokratis, tidak berat sebelah, namun jika sempat diganggu privasinya, Semar sering bertindak tegas, bahkan dewa pun sering dihajar.

Kyai Semar di dalam pedalangan juga sering disebut Badranaya, Dudamanangmunung, Ia menjadi pamomong trah keturunan witaradya. Ia menjadi manusia setengah dewa atau Bogasampir, karena Batara Ismaya tidak menetap di dalam tubuh Semar sebagaimana Sanghyang Wisnu yang menetap pada Sri Kresna. Sanghyang Ismaya tetap berada di kahyangan Sonyaruri, dan dalam keadaan tertentu jika di Arcapada terjadi sesuatu yang harus melibatkan dirinya, secara otomatis Batara Ismaya telah menyatu dengan Smarasanta.

Sebagaimana konsepsi Semar sebagai Badranaya, artinya berwajah rembulan, para caleg pun tampak mengidentikkan dirinya dengan berbagai dalih menjadi seperti rembulan. Rembulan itu, dalam konsepsi kepemimpinan Asthabrata, selalu dimaknai positif, yaitu pemimpin yang mau menerangi rakyat, lembut, dan menenteramkan hati yang dipimpin. Tampaknya, penggunaan estetika Semar, seakan menjadi senjata pamungkas caleg, mengingat kondisi Yogyakarta sebagai basis kota budaya. Ungkapan di reklame-reklame serta temu kader dengan masyarakat, dipoles dengan penuh damai. Para caleg dan tim suksesnya, biarpun memberikan sesuatu (kucuran dana) selalu dibumbui: "Menika ikhlas, dados boten dados, mangga dipunangge. Estu."Artinya, apakah ini ikhlas lahir batin, jadi caleg ataupun tidak, silahkan dipakai. Sungguh. Kata kunci ikhlas, tampaknya yang disadap dari Semar.

Kalau dicermati, kehidupan Semar, setelah perkawinan dengan Dewi Kanestri, dia pernah ditemui Sanghyang Ismaya dan ditugasi menjadi pamong trah keturunan witaradya (raja). Sebenarnya oleh Sanghyang Wenang, tugas itu diembankan pada Batara Ismaya, tetapi karena keturunannya sangat cocok untuk mewakilinya, akhirnya Batara Ismaya menunjuk Semar. Saat itu Semar bersedia karena suatu ketika Batara Ismaya tetap akan menjelma kepada dirinya. Selanjutnya Semar meminta kawan dan oleh Sanghyang Ismaya disanggupi. Bayang-bayang Semar disabda jadilah manusia yang 
dinamakan Bagong. Semar mulai mengasuh atau menjadi pamomong bagi keturunan Pandawa. Ia berkedudukan di kabuyutan Karangkadempel atau Klampis ireng.

Klampis ireng menurut Pak Usada (dalam Endraswara 2001), dari paguyuban penghayat Sapta Darma yang masih dalam proses penyelesaian, adalah gambaran otak manusia Jawa. Maksudnya, otak itu kalapis ireng, yaitu rambut manusia. Keunikan Semar oleh Supadjar (2001:377) dinyatakan sebagai figur kumawula, lambang rakyat-Gusti, sebab dia mengabdi pada Pandawa (Gusti). Para caleg yang hendak mengidentikkan dirinya sebagai Semar dalam merebut suara, memang cukup logis. Apalagi Yogyakarta juga pernah menjadi basis mistik kejawen (Endraswara 2001:12). Sebagai basis mistik dan kota budaya, paradigma berpikir mistis Semar dipandang dapat menyentuh hati rakyat.

Dalam konteks pewayangan dikenal lakon Semar Mbangun Kahyangan dan Resi Dhandhangseta, bahkan di era Soeharto muncul Semar Mbabar Jati Diri. Dalam kisah lain, yaitu lakon Saptaarga, Semar kemudian kawin dengan Dewi Kanistri (Kanastren), putri Batara Hira, keturunan Sanghyang Caturwarna putra Sanghyang Caturkanwakca. Peristiwanya diawali ketika Semar dikejar oleh dua ekor harimau betina sehingga ia berlari minta perlindungan Resi Kamunayasa di pertapaan Parewana. Harimau betina itu kemudian dipanah oleh Resi Kamunayasa dan berubahlah menjadi bidadari Dewi Kanastri dan Dewi Kaniraras. Dewi Kanastri kemudian kawin dengan Smarasanta, yang tidak lain adalah sebutan Semar.

Berbagai lakon wayang, selalu menuturkan watak kumawula dan pamomong Semar. Ki Hadi Sugito pun lagi-lagi dalam sulukan lagon jingking wetah, melukiskan Semar sebagai berikut.

\author{
titi tundha gagating ngarang \\ tri sunthi winayang jati, ong \\ kapat mangka kalima candhala, ae-ana \\ pepethite ula lanang, ong \\ pangiriding kebo dhungkul, sasisih sapi gumarang, ong, hong \\ (Kasidi 2009:221)
}

Maksudnya, sempurnalah Semar sampai meraih tiga dunia, yaitu dunia kesejatian. Empat dan lima nafsu telah dikalahkan dengan senjata ular jantan, kerbau dungkul, dan sapi gumarang. Kesuksesan Semar mbabar jati diri, dia dikenal orang Jawa sebagai figur anoraga, rendah diri, dan pamomong sejati. Melalui lakon Semar Boyong, Seno Sastroamijoyo (Haryanto 1992:68) menegaskan, Semar adalah lambang rakyat dan Pandawa (gusti). Menurut hemat saya, apabila caleg sebagai (Gusti) dapat memboyong Semar, jadilah dia wakil rakyat sejati.

Maka kearifan lokal Jawa pun bertebaran di beberapa spanduk dan kampanye oleh berbagai partai yang menyerupai nuansa Semar. Mereka ada yang pura-pura (lamis) hendak menjadi pamomong rakyat, penyambung aspirasi rakyat, dan seakan-akan hidup mati bersama rakyat. Setelah sukses menerbitkan buku Tahta untuk Rakyat (2004), tahun 2009 muncul lagi "buku putih" Sri Sultan HB X Bukan Reformasi tapi Restorasi, yang intinya juga menggiring ke arah estetika Semar. Beliau menganggap dirinya bukan "wong agung", melainkan hidup bersama rakyat dengan hamangku, hamengku, dan hamengkoni (Wirodono dan Nusantara 2009).

Hal demikian juga nampak penjilmaan imajinatif Semar, yang konon oleh Batara Ismaya disuruh momong witaradya (raja). Hal ini terkandung pesan, bahwa dengan estetika Semar itu, caleg dapat menjadi witaradya (pemimpin sejati). Menurut R Ng Ranggawarsita dalam Serat Witaradya dan Ajipamasa, konsep witaradya adalah pemimpin yang mampu mengayomi. Bagi pula dengan hadirnya pemimpin yang dibimbing Semar, diharapkan menjadi pemimpin rakyat sejati.

Itulah sebabnya, tak ketinggalan, GKR Hemas yang menjadi caleg DPD, juga menggunakan estetika Semar, hendak mempertahankan keistimewaan, Yogya yang santun berbudaya, sang pamomong rakyat sejati, dan mengadopsi keinginan generasi muda dengan semangat yang dipungut dari idiom tari ciptaan Sri Sultan HB I yaitu greget, sengguh, dan ora mingkuh hendak menjadi pamomong. 
Estetika Semar yang diolah GKR Hemas ternyata tidak sia-sia, karena berhasil menaklukkan lawan politiknya, hingga memperoleh suara fantastis. Mungkin, karena swarga nunut Ngarsa Dalem Sri Sultan HB X, yang membuat rakyat masih terformat budaya pengayom. Hasil yang fantastis itu, sebenarnya melekat estetika Semar, bahwa rakyat Yogyakarta tidak perlu dengan banyak alasan lagi lalu memilih Ratu Hemas. Harapan rakyat Yogyakarta, dengan memilih beliau, akan merasa terlindungi, aman, dan tenteram.

Budi Setya Nugraha dari PAN dengan dalih berkali-kali di media Kedaulatan Rakyat, merasa sebagai rakyat, bahkan bersumpah ingin menjadi pamomong sejati, yaitu tidak akan menyalahgunakan kedudukan jika kelak terpilih. Muara dari seluruh gagasan PKS dan Gerindra pun selalu menyertai kata-kata seperti hedak menjadi Semar ngejawantah, sebagai dewa penolong kesengsaraan rakyat. Rakyat yang sedang sakit, konon akan mereka obati bila pamomong sejati lahir dari PKS. Keberpihakan rakyat kecil, pedagang pasar tradisi, nelayan, selalu menjadi fokus Gerindra seperti ki Lurah Semar sedang mewejang ketiga anaknya, yaitu Gareng, Petruk, dan Bagong agar sendika dhawuh. Prabowo sebagai presiden Gerindra, dengan nada Soekarno kesiangan, selalu ingin bersama rakyat kecil, dengan mengkritisi dana trilliunan, yang diperuntukkan petani kurang 1\%. Semangat kapitalis yang mengobral janji ini, hendak membeli suara rakyat kecil lewat media "untuk mengajak terbang tinggi rakyat kecil setinggi terbang burung garuda", sayangnya dalam orasi selalu berestetika Semar yang semu: "Di negeri ini, yang maling teriak maling."

Yang lebih terang-terangan lagi, Rahmad Pribadi dari partai Golkar, di koran dan papan tempel menggunakan gambar Semar beserta punakawan lain yaitu Gareng, Petruk, dan Bagong, disertai katakata njawani "Pun klentu milih pamomong sejati." Ketika dia kampanye selalu dengan ungkapan bangkit desaku, jaya Jogjakaku, tentukan pamomong sejatimu, untuk Indonesia.

Penampilan tokoh yang memiliki reputasi nasional itu di samping untuk memberi kepercayaan rakyat, ada rasa kurang percaya diri, yang dipoles dengan gaya Semar, selalu meninggikan posisi bendara. Roy Suryo yang sudah terkenal di bidang informasi pun, tetap memanfaatkan estetika Semar, dengan cara menggunakan santun bahasa njawani: "Wong-wong Jogja, mangga contreng Roy Suryo." Bahkan pada putaran terakhir partai Demokrat di Alun-alun Utara Yogyakarta, Roy Suryo sempat memasang iklan politik Semar: "Sugeng Rawuh pak SBY, rakyat Jogja pun kleru contreng, Demokrat arsa mbabar jati dhiri kangge wong cilik." Konsep mbabar jati dhiri, sebenarnya idiomatik Semar di era orde baru, namun tetap dipandang penting di era reformis ini.

Panitia Pemilu pun di DIY ikut menggunakan estetika Semar, dengan mengenakan pakaian Jawa, seperti KPPS Sidaakur Sleman, KPPS Sindurejan, dan KPPS Bintaran Bantul. Bahkan di KPPS keraton, berusaha menghias TPS dengan kain batik. Dalih semacam ini, lebih diformat untuk mengatasi sindrom golput. Selain itu, masih ada gerakan perdamaian untuk Pemilu yang berorasi di perempatan jalan dengan mengusung ungkapan: "Kalah aja ngamuk, menang aja umuk."Artinya, kalah tidak marah dan jika menang tidak sombong.

Estetika Semar cenderung merujuk pada sikap yang pura-pura Jawa, bahkan Kejawen tulen. Mereka mencoba memanfaatkan produk kejawaan untuk pemenangan Pileg. Para calon yang mempolitisir budaya Jawa untuk tujuan kemenangan, kekuasaan, artinya telah mencoba berpikir analogis. Analogi bahwa dirinya hendak menjadi seperti Semar. Para caleg yang memanfaatkan mutiara kata dengan dalih mengolah kearifan tradisi, jelas menggunakan estetika Semar.

\section{Simpulan}

Dari tiga gaya pileg 2009, yaitu Sengkuni dan Semar tetap ada kekurangan dan kelebihan masingmasing. Kedua gaya ini tampaknya selalu menjadi gaman ampuh seorang caleg, untuk menaklukkan rakyat Yogyakarta. Setiap tipe rakyat, telah dibaca oleh caleg untuk menerapkan ketiga jurus itu. Untuk itu, dapat saya rumuskan tiga simpulan utama. 
Pertama, di era yang memang transisional politik ini, mungkin gaya Sengkuni yang lebih cocok, terlebih lagi pada sasaran rakyat (wong cilik). Gaya Sengkuni, merupakan rujukan jitu untuk merebut hati rakyat, setelah gaya lain tidak marketable. Ternyata, dengan Sengkuniologi, rakyat pun ada yang menyambut baik, mau menerima segala godaan. Hal ini berarti suasana politik sedang mencari bentuk. Biarpun cara semacam itu akan menuju ke jurang pembodohan demokrasi, toh rakyat memang tidak sedang berada pada suatu obsesi keluhuran.

Kedua, gaya estetika Semar, lebih mempan ditujukan kepada segmen masyarakat yang memegang teguh tradisi, terlebih para priyayi. Rakyat kecil pun ada yang tergiur, ketika idealisme mereka diunggulkan dengan trah Semar. Paling tidak, keterkaitan budaya kratonik, amat berpengaruh pula pada implementasi estetika Semar. Rakyat Yogyakarta yang awam dengan politik, bukan tidak mungkin kalau harus rubuh-rubuh gedhang, ikut pada tawaran estetika yang satu ini. Gaya estetika Semar, lebih menekankan pemimpin yang ngawula, berpihak pada rakyat.

Kedua gaya politik pileg Yogyakarta itu saya pikir tak ada yang lebih ampuh. Seluruhnya tergantung segmen masyarakat yang disasar. Hanya saja, jurus Sengkuni dan estetika Semar tampaknya yang nyaris paling disukai rakyat. Oleh karena, konsekuensi keduanya ini cenderung segera bisa dinikmati oleh rakyat.

\section{Daftar Pustaka}

Ahimsa PHS (2004) Strukturalisme Levi-Strauss; mitos dan karya sastra. Yogyakarta: Galang Press. Benson P (1993) Anthropology and literature. Chicago: University of Illinois Press.

Antlov H (2001) Elit desan dan orde baru dalam kepemimpinan Jawa. Jakarta: Yayasan Obor Indonesia.

Cederroth S (2001) Modernisasi orde baru dan Islam: aparat desa dan tokoh agama dalam kepemimpinan Jawa. Jakarta: Yayasan Obor Indonesia.

Endraswara S (2001) Mistik kejawen dalam kehidupan penghayat kepercayaan masa kini. Desertasi, Fakultas Ilmu Budaya, Universitas Gadjah Mada, Yogyakarta.

Harghana B dan Pamungkas PBA (2002) Bunga rampai wayang purwa beserta penjelasannya. Jilid 2. Sukoharjo: CV Cenderawasih.

Haryanto S (1992) Bayang-bayang Adiluhung: filsafat, simbolis dan mistik dalam wayang. Semarang: Dahara Prize.

Kasidi H (2009) Filsafat keindahan: suluk wayang kulit purwa gaya Yogyakarta. Yogyakarta: Bagaskara.

Keesing R (1992) Antropologi budaya: suatu perspektif kontemporer. Jakarta: Erlangga.

Mulyono S (1979) Wayang dan karakter manusia. Jakarta: Gunung Agung.

Ratna NK (2004) Teori, metode, dan teknik penelitian sastra. Yogyakarta: Pustaka Pelajar.

Ratna NK (2005) Sastra dan cultural studies: representasi fiksi dan fakta. Yogyakarta: Pustaka Pelajar.

Sarip (2009) Tembang Jawa. Yogyakarta: Dokumen pribadi.

Siong TT (2003) Sang Kuni: antologi cerpen. Yogyakarta: Narasi.

Sumantri B \& Kanti W (1999) Hikmah abadi: nilai-nilai tradisional dalam wayang. Yogyakarta: Pustaka Pelajar.

Supadjar D (2001) Semar super-super Semar dalam mawas diri. Yogyakarta: Philosophy Press.

Wirodono S dan Nusantara B (2009) Sri Sultan Hamengku Buwono X; bukan reformasi tetapi restorasi. Yogyakarta: Merti Nusantara Pustaka Utama.

Wellek R \& Austin W (1989) Teori kesusasteraan. Jakarta: Gramedia.

Sindhunata R (1981) Mengarang dengan estetika Semar. Seminar Sastra, tidak diterbitkan. 